mansasa

glyndŵn

Glyndŵr University

Glyndŵr University Research Online

Social Inclusion Research Unit

Social and Community

$1-1-2004$

\title{
Indigenous people, language and criminal justice: the experience of first language Welsh speakers in wales
}

Iolo Madoc-Jones

Glyndwr University, i.m.jones@glyndwr.ac.uk

Julian Buchanan

Glyndwr University, julianbuchanan@gmail.com

Follow this and additional works at: http://epubs.glyndwr.ac.uk/siru

Part of the Criminal Law Commons

Copyright (C) 2009 Routledge Taylor and Francis

This is an electronic version of the authors final version of an article published in Madoc-Jones, I., \& Buchanan, J. (2004) 'Indigenous people, language and criminal justice: the experience of first language Welsh speakers in wales'. Criminal Justice Studies, 17(4), 353-367. The final version of the article as published in the print edition of the Criminal Justice Studies Journal is available online at http://dx.doi.org/10.1080/1478601042000314874

\section{Recommended Citation}

Madoc-Jones, I., \& Buchanan, J. (2004) 'Indigenous people, language and criminal justice: the experience of first language Welsh speakers in wales'. Criminal Justice Studies, 17(4), 353-367

This Article is brought to you for free and open access by the Social and Community at Glyndŵr University Research Online. It has been accepted for inclusion in Social Inclusion Research Unit by an authorized administrator of Glyndŵr University Research Online. For more information, please 


\title{
Indigenous People, Language \& Criminal Justice: The Experience of First Language Welsh Speakers in Wales
}

\author{
Authors \\ Iolo Madoc-Jones is Acting Principle Lecturer in Criminal Justice Studies at the University of Wales, \\ North East Wales Institute. \\ Julian Buchanan is Reader in Community Justice at the University of Wales, North East Wales Institute
}

\section{Correspondence for both authors to:}

Department of Social Welfare and Community Justice, University of Wales, NEWI, Plas Coch, Wrecsam LL11 2AW. Tel: 01978 290666. Email: jonesim@newi.ac.uk and buchananj@newi.ac.uk

Iolo Madoc-Jones is Acting Principal Lecturer in Criminal Justice. He worked in Cheshire, United Kingdom as a Probation Officer, then Senior Probation Officer, before moving to an academic post as a lecturer in Social Work at the University of Wales, Bangor. He is a first language Welsh speaker whose practice career was with sex offenders and perpetrators of domestic violence. His MSc in Forensic Behavioural Science was obtained at the University of Liverpool and his continued academic interest is in the field of language, e-learning, effective practice with offenders and developing programmes of intervention. He has published in the British Journal of Community Justice, Probation Journal as well as a number of Social Work journals and presented papers at the British Criminology Conference and the Howard League for Penal reform.

Julian Buchanan is a Reader in Community Justice and Programme Leader for the BA Criminal Justice. He worked on Merseyside as a Probation Officer, Practice Teacher, Drug Specialist and Manager before moving to an academic post. He worked at the University of Liverpool where he was tutor for the Home Office probation route, the University of Central Lancashire where he set up an MA in Substance Misuse, before joining NEWI in August 2000. He has published a wide range of articles, research reports, and book chapters in relation to drugs, criminal justice, inclusion and discrimination. He is Series Editor for Issues in Criminal \& Community Justice, a member of the on the Probation Journal Editorial Board and Editorial Advisor to the British Journal of Community Justice. 


\title{
Indigenous People, Language \& Criminal Justice: The Experience of First Language Welsh Speakers in Wales
}

\begin{abstract}
This article examines the commitment of the Criminal Justice System for England and Wales to respond to the needs of the largest territorially bound linguistic minority group in the UK Welsh speakers in Wales. The article contextualises the experience of the Welsh speakers historically, making links with the experience of other indigenous national linguistic minorities worldwide. The importance of language choice is discussed and the reality of linguistic choice within the Criminal Justice System in Wales is explored in a small scale study with probation staff. Their responses to a brief questionnaire indicate that language choice is not a reality for the majority of Welsh speakers in Wales. The judicial and rehabilitative consequences of this lack of choice are explored. It is argued that a focus on non-discrimination in policy and practice at the international and national level, the vagueness of linguistic rights legislation and the centralisation of the criminal justice system in the UK leads to the oppression of Welsh speakers offenders in the criminal justice system in Wales. This article proposes that a passive approach to language choice for indigenous linguistic minorities like the Welsh is unacceptable and that a proactive commitment to linguistically sensitive practice should be adopted on the basis of social justice, equal opportunities and to effectively engage with offenders to protect the public. Nine principles for effective criminal justice practice with Welsh speakers in Wales are proposed which it is argued, have wider applicability with indigenous/substate national linguistic communities worldwide.
\end{abstract}




\section{Introduction}

Many of the worlds' languages are in decline. 5,000 of the world's 6,000 languages have less than 100,000 speakers (May 2000). According to Krauss (1995) 90\% of the world's languages are at risk of dying out during the twenty first century. This phenomenon is not naturally occurring. The overwhelming majority of threatened languages are the languages of socially excluded and oppressed national or ethnic groups who find themselves subordinated to a more powerful majority language. In response to this a significant number of United Nation declarations and instruments address the linguistic rights of indigenous/substate national (henceforth indigenous) peoples. The Universal Declaration of Human Rights, The International Covenant on Civil and Political Rights, the Rights of Person's Belonging to National, Ethnic, Religious and Linguistic Minorities all, in some way, address the issue of respecting the linguistic choices of indigenous peoples. In addition, at the European level the European Convention for the Protection of Human Rights and Fundamental Freedoms, The European Charter for Regional or Minority Languages, The Framework Convention for the Protection of National Minorities and the European Convention on Nationality, all place further expectations on member states to respect indigenous national language minorities within their territorial borders.

The criminal justice system is central in securing individual freedoms and protecting individual rights, and therefore international declarations and covenants are particularly wider-ranging in their provisions for the use of these minority languages within a judicial context. For example, the International Covenant on Civil and Political Rights, the European Convention for the Protection of Human Rights and Fundamental Freedoms, and the European Framework Convention for the Protection of National Minorities, all legally oblige signatories to ensure that individuals facing criminal charges are informed of the charges against them in their own language and are able to understand the court process. The United Kingdom (UK) Government is a signatory to these United Nations and European conventions. In light of this, this article explores the ability of the Criminal Justice System for England and Wales to respond to the needs of the largest historically situated, territorially bound, linguistic minority group in the UK -Welsh speakers in Wales. The article contextualises the experience of the Welsh speakers historically, making connections with experiences of other indigenous linguistic minorities. The importance of language is then explored along with the special status that is traditionally accorded to indigenous linguistic communities relative to migrant linguistic minorities in international human rights discourses. The legal provisions that are made for the Welsh language in Wales are discussed and the practicalities of linguistic choice within the Criminal Justice System in Wales are explored with probation staff. Their responses to a short questionnaire indicate that language choice is rarely available to Welsh speakers. The judicial and rehabilitative consequences of this situation are discussed. Some of the reasons for the lack of service provision for Welsh speakers are explored. It is argued that a focus on non-discrimination in policy and practice at the international and national level, the vagueness of international Human Rights legislation and the centralisation of the criminal justice system in the UK leads to the oppression of Welsh speakers in Wales. The article concludes by arguing that a proactive commitment to linguistically sensitive practice is long overdue on the basis of social justice, equal 
opportunities and to effectively engage with offenders to protect the public. Nine principles for effective criminal justice practice with Welsh speakers in Wales are proposed which it is argued, will have wider applicability with indigenous linguistic communities worldwide.

\section{The Oppression of the Welsh Language}

The marginalisation and 'otherness' of the Welsh language within the UK has its roots in history. The Welsh describe themselves as "Cymraeg" but the English word 'Welsh' is a derivative of the AngloSaxon term 'Waelas' meaning 'foreigners' or 'strangers'. In 1542 Henry VIII decreed that Wales would be incorporated within England, and under the much resented 'Acts of Union', the Welsh language was dismissed as English became the only officially recognised language in Wales. This ruling was further enforced by a ban that prevented all Welsh speakers from holding a public office. This institutionalised oppression of the Welsh language through the centuries forced the Welsh language to become an language without official status, only kept alive informally by Welsh speaking families, communities and chapels.

The $19^{\text {th }}$ century industrialisation posed a further threat to the language. The need for a more mobile workforce and specifically the influx of monoglot English speakers into the coal and slate mining areas of Wales - and later an influx of settlers and tourists into North Wales, had a significant effect on the cultural and linguistic landscape of the country. This colonisation typically involved demeaning portrayals of the 'conquered' nations culture and identity. Although the move to make Wales part of the British Commonwealth of Nations was generally subtle and didn't involve the overt violence associated with colonialisation in other parts of the world, this should not obscure the destructive impact of the imperialist attempts to rid Wales of its language and culture. The 'Report of the Commissioners of Inquiry into the State of Education in Wales' (1847), often referred to as the 'betrayal of the blue books', illustrates the insidious nature of the oppression;

'The Welsh Language is a vast drawback to Wales and a manifold barrier to the moral progress and commercial prosperity of its people. It is not easy to over-estimate its evil effects.' ( $p$. 66)

This was further enforced by the 1870 Education Act which made no provision for teaching through the medium of Welsh to first language Welsh speaking children in Wales, or for teaching the Welsh language generally. On the contrary, in some Welsh schools children were encouraged to identify and inform the teacher whenever they heard a child in their class speaking Welsh. The child caught speaking Welsh would then be required to wear a rope around her/his neck with a piece of wood attached inscribed with the letters 'WN' or 'Welsh Not'. At the end of lessons the child left wearing the 'Welsh Not' would be punished. This disturbing practice communicated to young children that speaking Welsh was so unacceptable it warranted punishment; it also ensured the dominance of English as a language associated with education and advancement. Given that Welsh was no longer an 
official language in Wales, employers such as the London and Northwest Railway Company operating in Wales felt justified for their policies of refusing to hire Welsh speakers. By the early 1900s to a large extent the Welsh language had been officially removed from education, employment and public life, and was confined to informal conversation. There was then, little benefit attached to learning and using the language and it inevitably became associated with unintelligence, immorality and barbarism, hardly surprising then that this systematic marginalisation of the language led to a decline of Welsh speakers that threatened the future of the language itself.

\section{The Importance of Language and Indigenous Languages}

In response to this threat, pressure groups such as the Welsh Language Society have sought to preserve the right of Welsh speakers to use their language. The advocacy has been based on three main arguments. Firstly that language has an instrumental value as the medium of discourse and communication. The vast majority of individuals who speak minority languages are multi or bilingual (Crystal 2000) However the ambilingual person (someone who shows equal competence in two or more languages), is relatively rare. Multi- or Bilingual speakers tend to have greater ability and comfort in one language (Davies 1994) and very often that is in the minority language.

Secondly whilst language is the primary medium for communication, it also influences how people project themselves and are received by others because language constructs identity. Studies in the field of linguistics (Whorf, 1956) have shown that the structure of particular languages influence the ways that speakers of a language know themselves and the way they understand the world around them. The ways in which different languages are constructed represent different meanings and conceptualisations of reality. Each language therefore has its own unique characteristics - what the Germans would call Sprachgefuhl or 'speech feeling', which directs its speakers towards a particular way of thinking about the world and their place within it. Each language shapes a particular identity for its speaker. For many minority language speakers a key aspect of their 'self' will be lost if they are required to interact through the second or even third language. Thirdly languages have embedded within them particular values, beliefs and ideas that reflect the social, economic, political and religious contexts in which the language has developed. Languages are therefore the repository of unique histories, ideas and traditions and the same moral arguments that justify conservation activity in the fields of zoology or biodiversity justify policies that seek to conserve minority languages.

For these reasons it is often argued that linguistic diversity should be encouraged and respected. However according to May (2000) minority languages worldwide have historically been marginalised in the process of nation state building. Linguistic and cultural assimilation came to be considered essential for ensuring political and national cohesion within state boundaries. For a short while such assimilationist objectives were endorsed at the international level- The International labour Organisations' 1957 Convention Concerning the Protection of Indigenous and Other Tribal and Semi- 
Tribal Populations in independent Countries for example was clearly assimilationist in tone. In some instances the drive towards national homogeneity was underpinned by the discourses of racism. Aboriginal peoples in Australia and Native Americans in the United States were subjected to organised genocidal policies aimed at National racial congruence. Welsh speakers in Wales along with linguistic minorities such as Basque speakers in Spain and Sami speakers in Norway on the other hand were subjected to organised linguicidal policies aimed at national linguistic and thereby cultural congruence. Common to almost all indigenous linguistic minorities are the experiences of their language and culture being assigned an inferior status, subordinate to the majority language and culture. State policies consigned the minority language to the informal sphere and some policies aimed to remove the language from the educational sphere. Variations on the "Welsh Not" for example were used with indigenous peoples in the United States (Baron 1990), Spain (Rubin 1968) and Scandanavia (Vik and Lars 1993). A further common experience is of injustice relative to the criminal justice laws of the majority culture.. They have been disproportionally arrested, prosecuted, found guilty and sentenced to custody or even death (Davis 1999, Zerrougui 2002). A consequence of this has been the extinction or demise of indigenous languages worldwide. In the Welsh context census figures indicate that $43.5 \%$ of the population spoke Welsh in 1901 but by 1991 this figure had dropped to $18.5 \%$ (circa 500,000 people).

More recently language death has been exacerbated by the advent of the mass media and the information age, the processes of globalisation, and the spread of majority language based multinationalism. Despite this however, in the context of the breakdown of old world orders and the activism about identity arising from this, from the development of a "rights consciousness" (Kymlika 2002), and fears about the spread of the same ethno-linguistic conflicts as have occurred in the former Yugoslavia and Soviet Union, indigenous peoples worldwide have wrought some linguistic concessions from majority communities. Many linguistic minorities worldwide have secured some national recognition of their linguistic needs either in written constitutions or laws e.g. Mirandese in Portugal, Frisian in the Netherlands, Basque in Spain and Quechua in Peru. According to Kymlika (2002) key to this process has been the growing recognition that assimialtionist policies have not worked, and indeed in some cases have exacerbated ethnic and linguistic tensions. Democracies have therefore felt the need to "search for a model of citizenship that can build common civic identities whilst simultaneously affirming cultural diversity" (Kymlika, 2002 p.13)

These concessions have largely been secured within a Human Rights discourse that stresses the special status of indigenous languages as opposed to linguistic minorities that exist as a result of migration. In the latter case a language will be in the minority due to the relative numbers of speakers that happen to migrate into a country. In the former case, it is recognised that a language is often in the minority as a result of a long standing systematic and institutionalised campaign of oppression accompanying colonisation. Migrating peoples often embrace language change as a positive developmental aspect of their migration to identify with their adopted nation. Indigenous peoples worldwide on the other hand 
have experienced the loss of opportunities to use their language as a result of strategic and deliberate linguicide.

Indigenous languages are often ascribed a special status at national and international level because they can claim a heritage within a nation that predate or coincide the formation of the modern state and its majority language. The status also derives from the particular way language and culture often become symbolically linked as other differences lessen due to exposure of the minority culture to majority influence. The special status is not simply on the basis of a pragmatic request to accommodate a linguistic minority (a case that could be made by numerous migrant languages), but on the need to protect and institutionalise the heritage of the minority language which has been embedded within the geography, identity and territory of the indigenous peoples.

In this contexts The UK Government introduced a Welsh Language Act in 1967. This Act recognised the official and special status of the Welsh language within Wales though it was not until another Welsh Language Act in 1993 that the Welsh language ban of the $16^{\text {th }}$ century was properly repealed. The 1993 Welsh Language Act placed some requirements on public bodies to provide services for Welsh speakers and stated specifically that in the conduct of business and administration of justice in Wales, the English and Welsh languages must be treated equally. Although the private and voluntary sectors were exempted from the Act and a clause also stated that the provision of Welsh language resources was only necessary as far as this was 'appropriate under the circumstances and... reasonably practicable' (section 5 (2)), the act marked a significant departure in terms of language policy in Wales. Not six months before its introduction for example in the case of EX parte Jenkins, Mr Justice Widgery felt able to comment;

"I think it is quite clear that the proper language for court proceedings in Wales is the English language. It is to my mind a complete misapprehension to believe that anybody at anytime has a right to require that the proceedings be conducted in Welsh" [1967] Q.B. 21.

The 1993 Welsh Language Act forms the centrepiece of the UK Governments five yearly reports to the Council of Europe on its action in respect of the Framework Convention for the Protection of National Minorities. Accordingly the adequacy of its provisions warrant scrutiny.

The Place of Language in the Criminal Justice System: The Welsh Experience

In order to explore day to day Welsh language provision within the criminal justice system a small pilot study was conducted that sought the views and experiences of staff working within an agency (the Probation Service) of the criminal justice system across the whole of Wales. The survey sought to 
explore how, and indeed if, the needs of Welsh language speakers in Wales was addressed within the criminal justice system. Although the findings of the study have particular relevance to the Probation Service, the study has relevance for the wider criminal justice system in Wales and indeed for indigenous linguistic communities worldwide. Permission was sought from the Chief Officers in each of the four areas of the Probation Service in Wales to send an electronic questionnaire to its entire staff regarding linguistically sensitive practice. Two chief officers indicated that they were willing for their staff to participate but with the condition that the questionnaire must be kept brief so as not to take up too much of its staff time. A single bilingual e-mail question was therefore sent to all staff in participating areas:

What in your opinion (and experience) are the issues that arise for the Probation Service in relation to responding to the needs of Welsh speaking staff and/or Welsh speaking offenders?

Respondents were assured that their replies would be collated and remain anonymised. The response rate of $15 \%$ was a little disappointing with 32 staff responding. Nine described themselves as first language Welsh speakers, four described themselves as being Welsh learners and the remaining staff identified themselves as speaking only English. Clearly the views obtained may not necessarily represent the views of the total Wales staff group, nor of the National Probation Service in Wales. However, the responses to the question do provide some interesting perceptions and valuable insights about the experiences of Welsh speaking staff and Welsh speaking offenders in Wales. What is presented is a representative range of the key issues identified in the returns in response to the question asked, and an interpretation of their relevance and meaning that is both historically and culturally informed.

The Welsh Language Board was established in December 1993 under the terms of the Welsh Language Act to promote and facilitate the use of the Welsh language in Wales. Under Section 38 of the Act public bodies providing services in Wales are required to submit language schemes to the Welsh Language Board detailing how they intend to implement the requirements of the Welsh Language Act in their operations. Most of the criminal justice agencies within Wales have submitted such plans to the Board and like other agencies in the criminal justice system, the probation services asserts that its policies and practices are linguistically sensitive. This is partly on the basis that people are offered a choice at the first point of contact as to their preferred language. In relation to offenders being offered a language choice the respondents in this study made the following comments;

No-one's ever asked for a service in Welsh-and I've been around for ten years

Some staff asked offenders what language they would like to be used with them - but most don't bother - the assumption is everyone speaks English anyway 
'Although staff know they should give clients the language options, in practise they rarely bring the issue up, unless the client specifically asks.'

The public must be able to choose the language they want to use when dealing with the probation service. This does not happen at this time

'The majority of our clients have moved here from England so Welsh language is not relevant to them, but I suspect that because so very very few of our clients speak any Welsh at all - we are very lazy about offering the option to anyone.'

'The main problems that I have personal experience of is that court staff in ours and other areas do not prioritise asking offenders if their preferred language is English or Welsh, they are more aware to ask if the offender is from a minority group but if Welsh then they assume that English is ok.'

'What language do you prefer is usually one question on an English language form that is usually asked of offenders once in court by an English speaker as they leave the dock having usually been forced to speak English in court. They may as well say 'you don't want a Welsh language service do you?'

'I have lots of offenders transferred to me who preferred to speak Welsh. When I ask them why they had originally said they preferred to speak English, they say they hadn't known that it meant they would have to speak English all the time'

From these comments it seems that despite the existence of Welsh language schemes, language choice is not always offered to offenders. It is also the case that when choice is offered it is not necessary framed in a way that is sensitive to the oppressive history and marginalised status of the Welsh language. Lynn and Adlam (1998) have noted how Welsh Language speakers are reluctant to elect a service in the medium of Welsh if the offer is made in English. This is easy to understand given the history of Wales and wider contemporary social discourses concerning the Welsh language. The choice is offered in the social and political context of the language being perceived as an inferior and largely insignificant informal language. It is easy then for Welsh speakers to feel 'a nuisance' to the dominant majority when requesting services in the Welsh language. Requesting Welsh language provision involves the Welsh-speaking offender having to embrace an identity that they may ordinarily feel under pressure to relinquish. Requesting a service through the medium of Welsh requires offenders who are in vulnerable positions, whose self esteem may already be low, and who know that their behaviour is under assessment, to risk the possibility of prejudice and discriminatory treatment from those in authority. According to Bourhis and Giles (1977) it is common for individuals in powerless situations to adapt their language in order to create a more favourable impression (accommodation theory). They 
stress how individuals in situations where they risk criticism, change languages and codes to prevailing norms. This anticipation of criticism is likely to influence the choices made by Welsh speaking offenders throughout the criminal justice process in Wales from the point of arrest, when an offender chooses which language they wish a police interview to be conducted, to the court hearing and beyond. Under Police regulations (HMSO 1998) Welsh speakers officially have the right to choose to be questioned by the Police in the medium of Welsh. Similarly Welsh speakers have had the right to choose a court hearing in the Welsh Language. Significantly, few defendants exercise these rights (Auld 2001). This may be linked to the fact that requesting the criminal justice process to be conducted through the medium of Welsh requires the offender to ask for a service that is out of the ordinary -one that has historically and culturally been seen as largely irrelevant and unnecessary. It is likely that similar restraints occur when witnesses decide which language they wish to give a statement to the police, or provide evidence in court. Ensuring that processes are conducted in a minority language requires a degree of assertion and sense of efficacy that is usually absent in a police station or courtroom setting. It is hardly surprising that few offenders request a Welsh language service. One respondent in the current study commented that they have worked for the probation service in Wales for ten years and not encountered a person who wished a Welsh language service. Comments from a Chief Officer in Wales to the request to engage with the current study highlights how Welsh language needs can be easily dismissed;

"There has been, to my knowledge, only one instance of an offender requesting that a pre-
sentence report be provided in Welsh within the past ten years and, when the case got to
court, that offender changed his mind and asked for an English copy to be presented"

The implication inherent in this response is that because so few offenders have requested a Welsh language service, language choice cannot be an issue in that particular probation area. This is despite the fact that this area contains above average numbers of Welsh speakers within its jurisdiction. An alternative explanation for the lack of service take up could be explained by a self fulfilling proposition due to the negative and inappropriate way Welsh language provision is offered. Lack of real choice and opportunity inevitably means that a service in the Welsh language is not requested. The poor take up is then used to argue that the service provision is unnecessary. The lack of positive and widespread availability of Welsh language provision then further alienates Welsh language speakers.

The respondents in this study highlighted how choice is further constrained by resource implications. Welsh speakers, electing a service in Welsh would be immediately aware that they run the risk of delaying the process and of being treated less favourably. The respondents made the following comments about the availability of staff able to speak Welsh

'This area has a Welsh language policy but it may as well not exist - there is only one Welsh speaker [member of staff] within 50 miles' 
'They keep asking offenders in which language they prefer to have their services but I am the only Welsh speaking member of staff this side of the county'

There is rarely a Welsh speaking member of staff at court. If someone wants to speak to a Welsh speaker they have to walk two miles to the office

'I think that Welsh speaking offenders in [my area] would have a really hard time because there are very few staff that speak Welsh'

In the probation context therefore requesting a Welsh language service raises difficulties. Services may be unavailable, delayed or involve the Welsh speaker having to inconvenience themselves through travel. In the courtroom environment or a police interview this could lead to serious financial and emotional ramifications for those caught up in the criminal justice system. A person electing a Welsh language police interview or court hearing could find themselves held in police custody, on bail or on remand for longer periods than their English speaking counterparts. The Dyfed-Powys police authority, one of the four police areas within Wales, recognise in their Welsh language scheme that parity of service cannot be provided in the police station, commenting in their Welsh language scheme that'

'If a fluent Welsh speaking member of staff is not immediately available, measures will be in place for Welsh speaking staff to be contacted.....If a detained person wishes to communicate in Welsh an interpreter will be provided..... 'Similarly persons attending police stations voluntarily for the purpose of assisting with investigations will also be provided with the facility of an interpreter.'

(Dyfed Powys Police Authority Welsh Language Scheme 1999)

At no point in the criminal justice process is language and identity as an important aspect of justice more acute, than at the point of imprisonment. The opportunity or right of language choice is non existent for a significant proportion of Welsh speaking offenders who are routinely incarcerated in English prisons. This prevents the Welsh speaking offender or child from accessing a linguistically sensitive service at a time of significant need, and forces them to engage with others in their second language, at a time of severe stress and crisis. This raises serious issues in terms of accurately assessing their risk of re-offending, risk of harm, addressing offending behaviour and it exacerbates the detrimental impact of imprisonment.

The respondents in the study highlighted that when offenders do elect a Welsh language service, the resource materials are often not available in the medium of Welsh. A number commented upon the inability to offer a bilingual service: 
as far as I know there is no Welsh language materials available-nothing for pre-sentence reports nor materials to work with offending behaviour-I have to complete supervision documents with Welsh speakers in English- shameful'

We have no bilingual programmes/programmes in Welsh nor the computer technology to support supervision in Welsh

it would be very difficult for them to fit into a group accredited programme or even to partake or learn in one

It actually gets very embarrassing. On the one hand offenders are told they can have their service in Welsh. On the other there is no material available to be used except in English and to get something translated you have to wait ages. Mostly offenders give up and take it in English

This lack of provision is often defended on the basis that they there are no Welsh language-speaking members of staff available, or a limited budget to translate materials into the Welsh language. The absence of such resources isn't inevitable or unavoidable; it reflects strategic priorities that give a little importance to bilingual provision. The impact of this low priority is a failure to make finance available for translating facilities, for Welsh language resources, and for attracting more Welsh speaking staff. As May indicates "the exclusion of minority languages is just as much a process of social engineering as their promotion" (2000, p.379).

In 2002 only $0.8 \%$ and $7.4 \%$ of police officers in the Gwent and South Wales areas of Wales respectively were able to speak Welsh even though $15 \%$ of the combined population could speak Welsh (Standing Committee on Welsh Language 2002). In these circumstances the inaction is not passive, impartial and without effect; it serves (consciously or unconsciously) to actively perpetuate the discrimination experienced by first language Welsh speakers within the criminal justice system. It also reflects the lack of understanding of the important justice issues surrounding bilingually sensitive practice. This lack of priority was commented upon in a study by the Welsh Language Board concerning the extent of Welsh language provision on web pages managed by criminal justice agencies in 2003 (Bwrdd-yr-Iaith 2003). The Welsh language did not figure at all on the web pages of the crown prosecution service nor in 4 of 5 police authorities or agencies. 


\section{The Consequences of Linguistic Discrimination in the Criminal Justice System}

Individuals who are required to express themselves in their second language are often prevented from expressing themselves fully. Pugh and Jones (1999) in their study of Welsh language and social work found that some clients conducted all their daily affairs through the medium of Welsh and consequently had poor command of formal English. These individuals could not adequately communicate their needs when services were offered in English only. Even when operating in their first language many people caught up in the criminal justice system don't find it easy to articulate their thoughts and feelings, but a first language Welsh speaker is likely to struggle further if they are forced to engage in the criminal justice system in Wales through a second language. It is possible they could find themselves in less favourable position than a speaker of a non-indigenous language that is provided with an interpreter because they have no command of the majority language.

Operating in a second language not only impairs the quality of communication, but in addition minority language speakers who are forced to use their second language may struggle to be fluent, and can easily feel that their sense of identity and confidence is being undermined. The Auld Report (2001) recognised this has serious implications throughout the court process; for witnesses giving evidence in their second language, for defendants presenting their defence, or during assessment by the probation service. Using a second language results in a loss of cognitive and emotional complexity and it increases the chances of being misunderstood or possibly being perceived as obstructive or evasive. In the courtroom this could have very serious consequences and lead to a defendant receiving a harsher sentence

Much of the rehabilitative work done with offenders is predicated upon therapeutic relationships and cognitive behavioural groupwork interventions. The core premise of cognitive behavioural approaches is that offending behaviour is the result of interplay between language and behaviour. The ability to access, analyse, and consider alternatives to the self instructional talk that underpins offending behaviour requires considerable skills to access the offender's primary language and language of thought. Requiring, directly or by default, an offender to engage in rehabilitative programmes in their second language will inevitably undermine the foundations of a therapeutic relationship, fail to model pro-social behaviour (Trotter 1990) and dilute the impact of any cognitive based intervention. This could seriously undermine the effectiveness of the programme.

\section{Protecting Language Rights}

The Welsh Language Act 1993 and indeed numerous international Human Rights declarations follow the Western philosophical convention of promoting freedom, democracy and choice. This theoretical view of freedom tends to be decontextualised and offers only the principle of choice, not the practicality of choice. Providing choice is complex and depends upon balancing the competing and sometimes conflicting rights of different groups; a balance between a loss of rights due to state 
interference, and the promotion individual freedoms from the state. Rights are primarily conceived in passive terms, as freedom from interference, as opposed to proactive provision of resources. This passive approach to rights becomes problematic in relation to language above all other rights, because as Kymlika and Patten (2003) note, when a government tries to secure the rights of other immigrant and indigenous language - it must of necessity do so in one language or another. The chosen language in effect becomes a proactive promotion of rights for those that speak that language - the members of the majority language group. According the minority group some passive freedoms to use their language does not equalise the position of the minority language nor address the reality of language diglossia.

Despite the fact that a number of international declarations recommend a positive obligation to promote language rights for example Article 1 of the UN Declaration on the Rights of People Belonging to National, Ethnic, Religious or Linguistic Minorities comments that states "shall adopt legislative and other measures" in order to protect the identity of minorities and to encourage conditions for its promotion, there exists what Alston states is

"a powerful presumption that community political activity in the field of human rights should be largely confined to negative prohibitions rather than positive initiatives" $(1999$, p.10)

This lack of proactive promotion of rights is more likely to be apparent in those areas where considerable prejudice against positive action exists. In relation to the Welsh language institutionalised discrimination is long standing and endemic - passive negative prohibitions are likely to have little impact upon the situation.

Little support is offered by the Framework Convention for the Protection of National Minorities of the Council of Europe which resembles a net, which is very wide-meshed and contains a large number of holes (Troebst 1998). Governments that intend to slip through this net can find justification for doing so within the framework and can also claim to be 'meeting international standards'. An apposite example of the vagueness is further illustrated by the European Convention on Human Rights and Fundamental Freedoms; articles 5(2) and 6(3) stress that a defendant should be informed 'in a language which he(sic) understands' the reasons and cause for the arrest. 'Understanding' in the bilingual or multilingual context however, is complex because most minority language speakers are bilingual. They may not however be ambilingual or competent to use their second language in the legal context.

A sensitivity and commitment to these issues is made more problematic by the fact that Welsh criminal justice priorities are not set in Wales but in England. Some devolution has taken place. The passing of the Governance of Wales Act 1998 marked a watershed in the history of Wales with the establishment of a Welsh Assembly based in Cardiff. As a result of this Act, secondary legislative powers were formally transferred from the UK Government to the devolved administration in Wales on 1 July 1999. The Welsh Assembly assumed most of the powers previously held by the Secretary of State for Wales - 
these included executive responsibility for education and training, health, economic development, social services and local government. The UK Government retained responsibility however, for overall economic policy, defence, and matters relating to the criminal justice system. No devolved powers were therefore conferred on the Welsh Assembly in relation to prisons, police, or criminal justice policy. In addition, just as the 1998 Crime and Disorder Act had created a Youth Justice Board for England and Wales, located in London, England; the Criminal Justice and Court Service Act 2000 created a single National Probation Service (NPS) for England and Wales, with its headquarters also centrally located in London. In Wales, Welsh speakers represent $20.5 \%$ of the population; but in England and Wales as a whole, Welsh speakers represent less than $1 \%$ of the population. It is possible to conclude on this statistical basis alone that the Welsh language would not be accorded a high priority within a criminal justice system for England and Wales. As Kymlika states (2002) assimialtionist policies have usually been pursued, sometimes unknowingly and by default, in circumstances where majority and minority groups co-exist. This is because it is often the case that minority linguistic communities statistically do not register on the political priorities of the majority and that respecting minority rights is inevitably experienced as destabilising by the majority, requiring as it does, some relinquishing of existing advantages and power. Many Western democracies have responded to the growth in diversity and failure to assimilate minorities into a coherent nation state by adopting forms of Government organised around the principles of communitarianism and multination federalism. According to Kymlika (2002) minority groups worlwide have only been able to secure genuine rights alongside such moves towards multination federalism. Such moves have supported self determination and a focus on regional concerns. In the Welsh context it is already clear that federalism has created a new focus on language rights. The Welsh Assembly Government has launched a National Action Plan for a Bilingual Wales called Iaith Pawb (Everybody's language) in 2003 with the wide-reaching aim of supporting and building upon language use amongst businesses, communities and individuals. No firm evidence is available after so short a period to evaluate the impact of devolution or "Iaith Pawb", however at the very least enabling forces are unleashed by such policies and devolution which places Welsh Language more positively and robustly on the equality agenda than ever before. The influence Welsh political philosophy and priorities have had on criminal justice however has been limited due to responsibility for this being reserved to England.

\section{Conclusion: Promoting Change}

As a result of the passive approach to bilingual provision, the vague wording and interpretation of international declarations, and the centralisation of power over Welsh criminal justice in England, it is argued that the deeply engrained institutionalised discrimination of the Welsh language in Wales continues and is reflected in the criminal justice system. The de facto status accorded to the Welsh language is largely no different from that pragmatically accorded to any minority migrant language. In the main, special arrangements have to be made to provide a bilingual service. Because of this Welsh language services or resources are infrequently demanded, leading to Welsh speaking offenders 
experiencing an inferior justice system than first language English speakers. This article has highlighted that such an approach is unlikely to be effective in addressing the requirement of justice, human rights, equal opportunities or tackling offending.

The authors believe that the presence of the Welsh and English languages in Wales must be adequately reflected within the criminal justice system operating in Wales. If bilingual Welsh language provision across the criminal justice system in Wales is to become a practical reality, it will require a robust strategy that produces positive and pro-active policies and practices. Equal opportunity in the criminal justice system needs to become a practical reality for Welsh speakers - both for those that work in the agencies as well as the victims, offenders and witnesses. The issue is more than one of human rights and equality. It is clear that without proper provision and engagement through the medium of Welsh the criminal justice system will fail to deliver justice and agencies within Wales will seriously undermine their ability to manage offending behaviour. Based upon an adaptation of Davies' (1994) suggestions for anti-oppressive practice in Wales, nine principles are proposed for criminal justice policy and practice as a starting point. These principles will also have wider applicability for indigenous linguistic communities worldwide.

i. Language is more than a means of communication: it is an essential part of an offender's culture and identity.

ii. Individuals are able to express themselves more effectively, accurately and comfortably, if they are able to communicate in their first language.

iii. Criminal Justice would be more suited to the community it served if it was devolved to the Welsh Assembly in Wales

iv. People in Wales have the right to engage with the criminal justice system through the medium of Welsh. In some areas this will necessitate 'Welsh essential' posts being created.

v. First language Welsh speaking offenders should be interviewed assessed and tried in Welsh without any delays unless an alternative is preferred, similarly Welsh speaking witnesses should be allowed to give their evidence in Welsh unless another language is requested.

vi. All criminal justice staff in Wales should have a basic ability in the Welsh language and be provided with opportunities to further develop their Welsh language skills.

vii. Welsh speaking offenders should be housed in local bilingual based penal institutions

viii. All education/training for criminal justice staff should be available fully bilingually.

ix. Public media (such as video, newspapers, leaflets, magazines and posters) in criminal justice agencies in Wales must reflect the bilingual nature and equal status given to English and Welsh.

6,815 words 


\section{References}

Alston P., (1999) The EU and Human Rights, Oxford University Press, Oxford

Auld, Lord Justice (2001) Review of the Criminal Courts of England and Wales. London, Stationary Office.

Baron, D (1990) The English Only Question: An Official Language for Americans? New Haven. Yale University Press.

Bourhis, R. Y. \& Giles, H. (1977). The Language of Intergroup Distinctiveness.

In H. Giles (Ed.), Language, Ethnicity and Intergroup Relations. London: Academic Press.

Bwrdd-yr-Iaith (2003) Individual Web Sites Survey accessed 27th July 2004, http://www.bwrdd-yriaith.org.uk/uploads/publications/412.htm

Commissioners of Inquiry into the State of Education in Wales (1847) Part II. Brecknock, Cardigan, Radnor, and Monmouth, London (871 XXVII) London. Great Britain. Parliament Sessional Papers 1847.

Crystal, D. (2000) The Cambridge Encyclopaedia of Language. Cambridge: Cambridge University Press.

Davies, E. (1994) They All Speak English Anyway. Cardiff: CCETSW.

Davis,B (1999) The Inappropriateness of the Criminal Justice System - Indigenous Australian Criminological Perspective. Paper presented at the 3rd National Outlook Symposium on Crime in Australia, Mapping the Boundaries of Australia's Criminal Justice System convened by the Australian Institute of Criminology and held in Canberra, 22-23 March 1999

Dyfed Powys Police Authority (1999) Welsh language Scheme. Dyfed Powys Police. Camarthen

Krauss, M (1995) language Loss in Alaska, the United States and the World. Alaska Humanities Forum $6(1) 2-5$

Kymlika, W (2002) Multiculturalism and Minority Rights: West and East. Journal of Ethnopolitics and Minority Issues in Europe. Issue 4 p.1-27

Kymlika, W and Patten, A (2003) A Language Rights and Political Theory. Oxford. Oxford University press

Lynn, E. \& Adlam, D.A. (1998) 'The Welsh language: Oppression and Probation Practice', in Probation Journal 45 (2), pp.73-77.

May, S (2000) Uncommon Languages: The challenges and Possibilities of Minority Language Rights. Journal of Multilingual and Multicultural Development. Vol 21, No5

HMSO (1998) Police and Criminal Evidence Act 1998. London. HMSO Home Office

Pugh, R and Jones,E. (1999) 'Language and Practice: minority language provision within the guardian ad litum service'. British Journal of Social Work, 29 (4). pp. 529-45.

Rubin, J (1968) National Bilingualism in Paraguay, Mouton, den Haag, Netherlands.

Standing Committee on the Welsh Language (2002) A report of the Criminal Justice Sub-committee on the Use of the Welsh language in the Criminal Justice System in Wales. London. Lord Chancellor's Department. 
Troebst, S (1998) The Council of Europe's Framework Convention for the Protection of National Minorities Revisited: Paper given at the 30th National Convention of the American Association for the Advancement of Slavic Studies, Panel 5-28: "Europe and the Protection of National Minorities", Boca Raton, Florida, 24 to 27 September 1998

Trotter, C. (1990) 'Probation can work: A research study using volunteers', in Australian Social Work, 43 (2), pp. 1-6.

Vik, R and Lars, S. (1993) The Nordic languages: Their Status and Interrelations. Oslo. Novus Press. Whorf, B. L. (1956) Language, Thought and Reality (ed. J. B. Carroll). Cambridge, MA: MIT Press.

Zerrougui, L (2002) Discrimination in the Criminal Justice System. Office of the High Commissioner for Human Rights. Geneva. (E/CN.4/Sub.2/2002/5) 